\title{
Relation between electrocardiographic repolarisation changes and mechanical events in left ventricular hypertrophy
}

\author{
R B MOORE, L M SHAPIRO, D G GIBSON \\ From the Department of Cardiology, Brompton Hospital, London
}

SUMMARY The relation between ventricular function and the presence of electrocardiographic "strain" in patients with left ventricular hypertrophy was examined using digitised M mode echocardiography and 12 lead electrocardiograms in 64 patients with pressure overload, 21 with hypertrophic cardiomyopathy, and 14 athletes. Although all had increased left ventricular mass, those with strain had a prolonged interval from minimum cavity dimension to mitral valve opening and a reduced rate of early diastolic posterior wall thinning and dimension increase compared with those with normal ST segments and T waves. Both groups had normal systolic function (fractional shortening and peak velocity of circumferential fibre shortening), and the time between the termination of the $\mathrm{T}$ wave and minimum dimension was similar. In athletes, however, electromechanical systole was shorter than normal, and the end of the $\mathrm{T}$ wave and minimum cavity dimension were synchronous.

It is concluded that abnormal electrical recovery in left ventricular hypertrophy is closely related to impaired early relaxation amd may be dissociated from impaired systolic function, cavity dimension, interventricular conduction delay, and the presence of increased mass alone. The normal relation between electrical and mechanical systole is preserved even when the polarity of repolarisation is reversed.

Left ventricular hypertrophy has long been known to be associated with repolarisation electrocardiographic changes termed "strain." They have been the subject of investigation since the early part of the century when Einthoven observed their presence in patients with cardiac hypertrophy. ${ }^{1}$ The association remains clinically important. The strain pattern is the most satisfactory electrocardiographic evidence of left ventricular hypertrophy and is frequently used as the basis for making clinical decisions in individual patients. Removal of the cause of the hypertrophy leads to regression of $T$ wave changes in a substantial number of patients, particularly the young, ${ }^{2}$ over a period of weeks or months. Nevertheless, these repolarisation changes are non-specific, occurring in other conditions such as coronary artery disease or with drugs such as digitalis preparations. They are labile and may develop in otherwise normal subjects

Requests for reprints to Dr D G Gibson, Brompton Hospital, London SW3 6HP.

Accepted for publication 3 July 1984 in association with ill defined physiological stimuli such as hyperventilation. Finally, neither the genesis of the normal upright $T$ wave nor that of its inversion in these different conditions has been satisfactorily explained..$^{3-5}$ The present study aimed at investigating some of these questions by examining anatomical and physiological correlations of $T$ wave changes in a large series of patients with left ventricular hypertrophy.

Patients and methods

\section{STUDY GROUPS}

Ninety-nine subjects with left ventricular hypertrophy (posterior wall or septal thickness greater than the $95 \%$ confidence limits of normal) were studied. They were divided into the following subgroups:

Left ventricular outflow tract obstruction-39 patients (12 female and 27 male) had severe aortic stenosis requiring valve replacement (aged 6-82 years) and five (two female and three male) subvalvar aortic stenosis (aged 11-33 years). Three patients had open aortic 
valvotomy performed during childhood with subsequent recurrence of outflow tract obstruction. Those with more than minor aortic regurgitation or mitral valve disease or exertional chest pain were excluded. One patient with subvalvar stenosis had undergone surgical repair during infancy. Coronary arteriography was performed in 13 patients over the age of $\mathbf{4 0}$ years, and none had more than minor arterial narrowing. Five were taking digoxin.

Hypertension-nine patients (three female and six male) had coarctation of the aorta (aged 14-30 years) and 11 (three female and eight male) severe essential hypertension (systolic blood pressure $>185 \mathrm{~mm} \mathrm{Hg}$ (aged 37-65 years).

Hypertrophic cardiomyopathy-21 patients (11 female and 10 male) (aged 6-66 years) had a diagnosis based on the presence of typical clinical, electrocardiographic, and echocardiographic features. ${ }^{67} \mathrm{Car}-$ diac catheterisation was performed in seven, and all had normal coronary arteries. Twelve were taking beta blocking agents and two a calcium antagonist.

Athletes-14 top class male athletes (aged 19-34 years $^{8}$ participating in various sports including swimming, running, canoeing, and judo were studied.

\section{CONTROL GROUP}

Fourteen healthy normal subjects (four female and 10 male) aged 22 to 50 years were also studied.

\section{ELECTROCARDIOGRAPHY}

Standard 12 lead electrocardiograms were recorded within seven days of echocardiography with patients in the supine position during quiet respiration using a Hewlett-Packard (model 1511B) single channel or a Cambridge (model 3038/2) Series C three channel recorder. The following measurements were made: (a) mean frontal plane QRS axis, (b) mean frontal plane $T$ wave axis, $(c)$ sum of the $S$ wave in $V 1$ and $R$ wave in V5 or V6, (d) QT interval (initial QRS deflection to end of T wave), (e) QRS duration, and $(f)$ heart rate. The $Q R S$ voltage was considered to be increased if SV1+RV5 or RV6 was $>35 \mathrm{~mm}$ in adults and $>45 \mathrm{~mm}$ in children. A strain pattern was identified as ST segment depression $(>1.0 \mathrm{~mm})$ and $T$ wave flattening or inversion in the lateral or inferior leads. No measurements were made on extrasystoles or postextrasystoles. All patients were in sinus rhythm without bundle branch block. Three complexes per tracing were measured and the mean results obtained. No attempt was made to correct the QT interval for heart rate. Heart rates from the electrocardiogram were compared with those from the echocardiogram.

ECHOCARDIOGRAPHY

$M$ mode echocardiograms were recorded with Cam- bridge Instruments equipment using a $2.25 \mathrm{MHz}$ transducer. The patients were studied in the left semilateral position, and simultaneous electrocardiograms and phonocardiograms were recorded at a paper speed of $100 \mathrm{~mm} / \mathrm{s}$. Records of the left ventricular cavity were taken at the level of the tips of the mitral leaflets showing cusp separation. Aortic valve closure $\left(A_{2}\right)$ was taken as the onset of the first high frequency vibration of the second heart sound. $A_{2}$ was not recognised in most patients with aortic stenosis. Echocardiograms were digitised ${ }^{9}$ using a Summagraphics digitiser and a Prime 750 computer system. Three cardiac cycles were measured and the mean values obtained. The following measurements were obtained: (a) maximum (Dd) and minimum (Ds) left ventricular dimension and fractional shortening calculated as (Dd-Ds)/Dd; (b) thickness of the posterior wall (PW) at minimum cavity size (PWs) and at the onset of QRS (PWd)-percentage systolic thickening of PW was calculated as (PWd-PWs/PWd) 100; (c) ventricular septal thickness at the onset of $Q R S$ (VS); (d) peak rate of increase of dimension during early diastole $(\mathrm{cm} / \mathrm{s}) ;(e)$ peak rate of thinning of posterior wall during early diastole $(\mathrm{cm} / \mathrm{s}) ;(f)$ peak rate of reduction of dimension during ejection, normalised to unit dimension (peak velocity of circumferential fibre shortening $\mathrm{s}^{-1}$ ) and $(g)$ the following time intervals: ( $i$ ) The cycle length between successive $Q$ waves and heart rate; (ii) $Q$ wave to minimum left ventricular dimension, the point in late systole when the first derivative of cavity dimension first changes from negative to positive (QMD); (iii) $Q$ wave to aortic valve closure $\left(\mathrm{QA}_{2}\right)$; (iv) $\mathrm{Q}$ wave to mitral valve opening (QMO); $(v) \quad A_{2}$ to mitral valve opening (isovolumic relaxation period, IVR); (vi) minimum dimension to mitral valve opening (MDMO); (vii) end of $\mathrm{T}$ wave to minimum dimension (MD-QT), calculated as the difference QMD-QT; and (viii) $Q$ wave to peak posterior wall thickness, the point when the first derivative of posterior wall dimension first changes from negative to positive (TPTH). Left ventricular mass was calculated by using the cube formula: $\mathrm{LV}$ mass $=1.055(\mathrm{VS}+\mathrm{PW}+\mathrm{Dd})^{3}-(\mathrm{Dd})^{3}$.

\section{STATISTICAL METHODS}

Data are expressed as mean (one standard deviation). Comparison of mean values was made using Student's $t$ (unpaired) or the Mann Whitney U test. Linear regression was calculated by the method of least squares.

\section{Results}

\section{ELECTROCARDIOGRAPHY}

Sixty eight of the $99(69 \%)$ subjects satisfied the voltage criteria of left ventricular hypertrophy. Two 
normal subjects also fulfilled these criteria. Fifty eight (59\%) subjects had an electrocardiographic strain pattern. In athletes, six (43\%) met the voltage criteria for hypertrophy, but the ST segment and T waves were normal in all. Table 1 shows the electrocardiographic findings of all the adults. The QRS axis in the groups with aortic stenosis, -hypertrophic cardiomyopathy, and hypertension was significantly to the left of normal $(p<0.05)$, but there was no difference between the mean $T$ wave axis in the various patient groups and athletes.

Athletes had a mean heart rate of $60(9)$ beats/min, which was not statistically different from that of the normal subjects. The patients with outflow obstruction and hypertension had slightly higher rates 75 (14) beats/min and $72(15)$ beats/min respectively $(p<0.05)$. The QT interval was normal in all groups except in those with hypertrophic cardiomyopathy, where it was prolonged $(p<0.05)$. Beta blocking therapy in the groups with hypertension and hypertrophic cardiomyopathy did not influence either the cycle length or the QT interval. The QRS duration was longer in patients with outflow obstruction $(\mathrm{p}<0.05)$ and hypertrophic cardiomyopathy $(\mathrm{p}<0.01)$.

\section{LEFT VENTRICULAR FUNCTION}

Mean values of left ventricular dimensions were within normal limits in all groups of patients except for those with hypertrophic cardiomyopathy in whom the values were lower $(p<0.05)$, and in athletes, in whom they were higher $(p<0.01)$ (Table 2$)$. Left ventricular mass and by definition posterior wall thickness were significantly increased in all groups. Fractional shortening was reduced in the group with hypertension $(p<0.05)$; in all other patients both fractional shortening and peak velocity of circumferential fibre shortening were normal. The peak rate of dimension increase was greater than normal in athletes $(p<0.01)$ but was reduced in all groups of patients $(p<0.001)$. The peak rate of posterior wall thinning in patients with pressure overload and hypertrophic cardiomyopathy was significantly reduced $(p<0.05)$. There was significant prolongation of the interval from minimum cavity dimension to

Table 1 Electrocardiographic findings (adults)

\begin{tabular}{|c|c|c|c|c|c|}
\hline & Normal subjects & $\begin{array}{l}L V \\
\text { outflow } \\
\text { obstruction }\end{array}$ & Hypertensiont & $\begin{array}{l}\text { Hypertrophic } \\
\text { cardiomyopathy }\end{array}$ & Athletes \\
\hline $\begin{array}{l}\text { No of subjects } \\
\text { Voltage (mV) } \\
\text { Heart rate (beats/min): }\end{array}$ & $\begin{array}{l}14 \\
27(9)\end{array}$ & $\begin{array}{l}30 \\
50(17)^{\star \star}\end{array}$ & $\begin{array}{l}14 \\
43(13)^{\star \star}\end{array}$ & $\begin{array}{l}20 \\
39(15)^{\star}\end{array}$ & $\begin{array}{l}14 \\
35(6)\end{array}$ \\
\hline $\begin{array}{l}\text { Electrocardiogram } \\
\text { Echocardiogram } \\
\text { QT interval (ms) } \\
\text { QRS duration (ms) } \\
\text { QRS axis (degrees) } \\
\text { T wave axis (degrees) }\end{array}$ & $\begin{array}{l}63(11) \\
58(9) \\
375(35) \\
80(11) \\
52(21) \\
30(14)\end{array}$ & $\begin{array}{l}75(14) \\
72(13)^{\star \star} \\
370(29) \\
90(12) \\
11(28)^{\star \star \star} \\
58(109)\end{array}$ & $\begin{array}{l}72(15) \\
68(14)^{\star} \\
395(55) \\
90(13) \\
11(39)^{\star \star} \\
45(91)\end{array}$ & $\begin{array}{l}65(13) \\
58(9) \\
405(40)^{\star} \\
90(9) \\
20(40)^{\star} \\
76(105)\end{array}$ & $\begin{array}{l}60(9) \\
54(6) \\
375(44) \\
85(10) \\
55(15) \\
45(28)\end{array}$ \\
\hline
\end{tabular}

Difference from normal ${ }^{\star} \mathrm{p}<0.05,{ }^{\star \star} \mathrm{p}<0.01,{ }^{\star \star} \mathrm{p} p<0.001$.

Hypertension includes those with coarctation.

LV, left ventricular.

Table 2 Echocardiographic results

\begin{tabular}{|c|c|c|c|c|c|}
\hline & Normal subjects & $\begin{array}{l}L V \\
\text { oufflow } \\
\text { obstruction }\end{array}$ & Hypertension & $\begin{array}{l}\text { Hypertrophic } \\
\text { cardiomyopathy }\end{array}$ & Athletes \\
\hline $\begin{array}{l}\text { No of subjects } \\
\text { Left ventricular mass }(\mathrm{g}) \\
\text { Posterior wall thickness }(\mathrm{cm}) \\
\text { Left ventricular dimension }(\mathrm{cm}) \text { : } \\
\text { Diastolic } \\
\text { Systolic } \\
\text { Fractional shortening }(\%) \\
\text { Peak velocity of circumferential fibre } \\
\text { shortening }\left(\mathrm{s}^{-1}\right) \\
\text { Peak rate }(\mathrm{cm} / \mathrm{s}): \\
\text { Dimension increase } \\
\text { Wall thinning } \\
\text { Isovolumic relaxation period } \\
\text { Minimum dimension to mitral valve } \\
\text { opening }\end{array}$ & $\begin{array}{l}14 \\
161(53) \\
0.8(0.2) \\
4.8(0.3) \\
3.0(0.3) \\
39(7) \\
2.6(0.6) \\
15.3(3.3) \\
7.6(2 \cdot 1) \\
56(13) \\
30(24)\end{array}$ & $\begin{array}{l}44 \\
413(227)^{\star} \\
1 \cdot 6(0 \cdot 3)^{\star \star \star} \\
4 \cdot 6(1 \cdot 2) \\
3 \cdot 1(1 \cdot 1) \\
33(11) \\
2 \cdot 2(1 \cdot 1) \\
8 \cdot 1(2 \cdot 5)^{\star \star \star} \\
4 \cdot 4(1 \cdot 4)^{\star \star \star} \\
\mathrm{NC} \\
79(32)^{\star \star \star}\end{array}$ & $\begin{array}{l}20 \\
357(135)^{\star \star \star} \\
1.4(0.2)^{\star \star \star} \\
4.6(0.6) \\
3.3(0.6) \\
30(9)^{\star} \\
1.8(0.6) \\
7.7(3 \cdot 1)^{\star \star \star} \\
4.8(1.6)^{\star} \\
86(27)^{\star} \\
82(42)^{\star \star}\end{array}$ & $\begin{array}{l}21 \\
265(107)^{\star \star \star} \\
1.4(0.3)^{\star \star \star} \\
4.0(0.8)^{\star \star \star} \\
2.5(0.6)^{\star} \\
37(8) \\
2.4(0.7) \\
8.3(2.6)^{\star \star \star} \\
5.0(1 \cdot 7)^{\star} \\
94(23)^{\star \star \star} \\
113(37)^{\star \star \star}\end{array}$ & $\begin{array}{l}14 \\
434(106)^{\star \star \star} \\
1.3(0.2)^{\star \star \star} \\
5.8(0.6)^{\star \star \star} \\
3.7(0.6)^{\star \star} \\
37(6) \\
2.4(0.5) \\
16.1(3.8)^{\star \star} \\
9.4(3.5)^{\star} \\
54(29) \\
57(39)\end{array}$ \\
\hline
\end{tabular}

Difference from normal ${ }^{\star} p<0.05,{ }^{\star \star} p<0.01,{ }^{\star \star \star} p<0.001$.

NC, not calculated; $\mathbf{L V}$, left ventricular. 

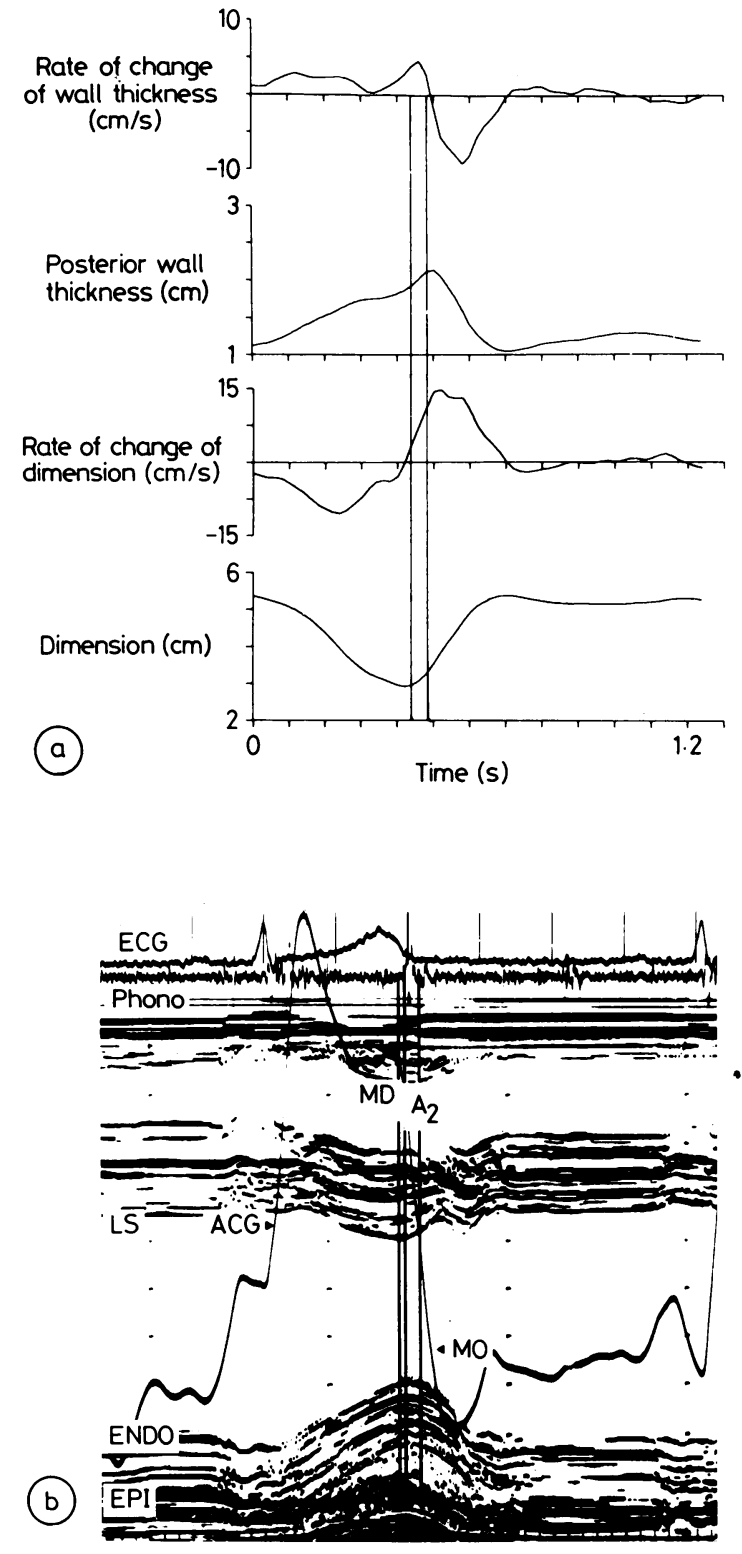

Fig. 1 (a) Set of computer plots from (b) digitised echocardiogram recorded simultaneously with an electrocardiogram (ECG), apexcardiogram (ACG), and phonocardiogram (Phono) in a 26 year old endurance swimmer. The two vertical lines on the plots correspond to aortic valve closure $\left(A_{2}\right)$ and mitral valve opening $(M O)$, the latter determined from another complex and occurring $60 \mathrm{~ms}$ after minimum cavity dimension $(M D)$ (shown in (b)). $L S$, left side of septum; ENDO posterior wall endocardium; EPI, epicardium. Note the rates of dimension increase and posterior wall thinning in early diastole. mitral valve opening and isovolumic relaxation period in all groups $(p<0.01)$ with hypertrophy except the athletes, who were normal (Fig. 1).

\section{RELATION BETWEEN MECHANICAL AND ELECTRICAL EVENTS}

Subjects with and without an electrocardiographic strain pattern were compared (Table 3); all those with left ventricular hypertrophy were studied as a group. Since all athletes were without strain and nearly all patients with hypertrophic cardiomyopathy had an abnormal electrocardiogram, a more homogeneous subgroup with pressure overload (outflow obstruction and hypertension) was also examined separately. When all those with left ventricular hypertrophy are considered, those with strain had a reduced rate of dimension increase $(p<0.001)$, reduced rate of wall thinning $(p<0.001)$, prolonged minimum dimension to mitral valve opening $(p<0.001)$, reduced peak velocity of circumferential fibre shortening $(p<0.05)$, and reduced percentage posterior wall thickening $(p<0.05)$. In patients with pressure overload, those with strain had increased posterior wall thickness $(p<0.01)$ and left ventricular mass $(p<0.001)$; fractional shortening and peak velocity of circumferential fibre shortening were reduced $(p<0.05, p<0.01)$. The peak rate of dimension increase was similar in the two groups but in both was significantly reduced from normal. Peak rate of thinning of the posterior wall was reduced $(p<0.01)$ and minimum dimension to mitral valve opening prolonged $(p<0.001)$ in those with strain (Fig. 2). The exclusion of patients taking digoxin did not affect the results. The division of patients into those with or without the voltage criteria of left ventricular hypertrophy did not show any differences in function.

The electrocardiographic measurements (heart rate and $\mathrm{QT}$ and $\mathrm{QRS}$ duration) and measured QT to minimum dimension were similar in those with and without repolarisation abnormalities regardless of medication.

The QT interval was shorter than electromechanical systole measured as the $Q$ wave to minimum dimension in all groups except the athletes. The mean value of cycle length of all subjects from the electrocardiogram and echocardiogram was similar (878(170) $\mathrm{ms}$ and 932(176) ms respectively, NS). In order to avoid any correction of QT interval for ages electrocardiographic and echocardiographic measurements were compared only in adult patients. The interval between the end of QT and time to minimum dimension (MD-QT) was similar in all patients and normal subjects (Table 4). In the athletes, MD-QT was less than normal $(p<0.01)$ because at any given heart rate electromechanical systole ended earlier $(p<0.05)$. As the period of electromechanical systole 
is closely related to cycle length ${ }^{10}$ an expected estimate of $Q$ wave to minimum dimension (QMD) for the athletes using the regression equation $(\mathrm{Q} M D=0 \cdot 29(\mathrm{RR})+170 \mathrm{~ms})$ obtained in normal subjects $^{11}$ is close to the value found in our normal subjects (Table 4).

\section{Discussion}

Left ventricular hypertrophy may be defined in several ways. The diagnosis might be applied to any patient with a left ventricular mass greater than the upper $95 \%$ confidence limit of normal. This criterion is fulfilled by many patients with coronary artery disease $^{12}$ as well as those in whom the left ventricular cavity is dilated, even though wall thickness is normal. ${ }^{13}$ We have used a more restrictive definition and have considered only patients in whom wall thickness is increased above normal values. In addition, we have excluded all patients with significant volume overload due to valvar regurgitation or a shunt. No patient had clinical or cardiographic evidence of coronary artery disease. Coronary arteriography was not, however, performed in all patients, so that clinically silent coronary artery disease cannot be excluded, but since more than $40 \%$ were aged less than 40 years and since the pattern of diastolic wall motion occurring in coronary artery disease is distinguishable from that occurring in hypertrophy, we do not feel that this lack of information appreciably influenced our results. Only a small minority of our patients were being treated with a digitalis preparation, and these were considered separately. The subjects studied finally fell into three groups; athletes with physiological hypertrophy, patients with hypertrophic cardiomyopathy (primary hypertrophy), and those with hypertrophy secondary to increased resistance to ejection resulting from aortic stenosis, hypertension, or coarctation of the aorta.

Previous studies have shown that $\mathrm{T}$ wave changes on the electrocardiogram are strongly associated with an increase in left ventricular mass. ${ }^{14}$ We were able to confirm this finding in the patients with secondary left ventricular hypertrophy and hypertrophic cardiomyopathy. Nevertheless, the athletes with an equal degree of hypertrophy all had normal electrocardiograms. An increase in left ventricular mass or wall thickness is thus not a sufficient condition for the development of repolarisation changes.

Long standing left ventricular hypertrophy may be

Table 3 Comparison of patients with or without electrocardiographic strain pattern

\begin{tabular}{|c|c|c|c|c|}
\hline & \multicolumn{2}{|c|}{ Pressure overload } & \multicolumn{2}{|c|}{ Left ventricular hypertrophy } \\
\hline & Without strain & With strain & Without strain & With strain \\
\hline $\begin{array}{l}\text { No of subjects } \\
\text { Left ventricular mass }(\mathrm{g}) \\
\text { Posterior wall thickness }(\mathrm{cm}) \\
\text { Left ventricular dimension }(\mathrm{cm}) \text { : }\end{array}$ & $\begin{array}{l}23 \\
284(102) \\
1.4(0.2)\end{array}$ & $\begin{array}{l}41 \\
457(220)^{\star \star \star} \\
1.6(0.3)^{\star \star}\end{array}$ & $\begin{array}{l}40 \\
338(124) \\
1.4(0.2)\end{array}$ & $\begin{array}{l}59 \\
397(213) \\
1.5(0.3)\end{array}$ \\
\hline $\begin{array}{l}\text { Diastolic } \\
\text { Systolic } \\
\text { Fractional shortening (\%) } \\
\text { Velocity of circumferential fibre shortening }\left(\mathrm{s}^{-1}\right) \\
\text { Peak rate }(\mathrm{cm} / \mathrm{s}) \text { : }\end{array}$ & $\begin{array}{l}4.2(0.6) \\
2.7(0.7) \\
36(9) \\
2 \cdot 5(1.0)\end{array}$ & $\begin{array}{l}4.8(1 \cdot 2)^{\star \star} \\
3.4(1 \cdot 0)^{\star \star} \\
29(10)^{\star} \\
1.8(0.8)^{\star \star}\end{array}$ & $\begin{array}{l}4.7(1.0) \\
3.1(0.8) \\
36(9) \\
2.4(0.9)\end{array}$ & $\begin{array}{l}4 \cdot 6(1 \cdot 1) \\
3 \cdot 1(1 \cdot 0) \\
32(10) \\
2 \cdot 0(0 \cdot 8)^{\star}\end{array}$ \\
\hline $\begin{array}{l}\text { Dimension increase } \\
\text { Wall thinning } \\
\text { Minimum dimension to mitral valve opening } \\
\text { Heart rate (beat/min): }\end{array}$ & $\begin{array}{l}8 \cdot 7(2 \cdot 5) \\
5 \cdot 2(1 \cdot 7) \\
63(21)\end{array}$ & $\begin{array}{l}7.6(2 \cdot 7) \\
4 \cdot 2(1 \cdot 2)^{\star \star} \\
90(37)^{\star \star \star}\end{array}$ & $\begin{array}{l}11 \cdot 1(4 \cdot 8) \\
6 \cdot 6(3 \cdot 2) \\
63(29)\end{array}$ & $\begin{array}{l}7 \cdot 9(2 \cdot 7)^{\star \star \star} \\
4 \cdot 5(1 \cdot 5)^{\star \star \star} \\
98(39)^{\star \star \star}\end{array}$ \\
\hline $\begin{array}{l}\text { Electrocardiogram } \\
\text { Echocardiogram } \\
\text { Q wave to peak posterior wall thickening (ms) } \\
\text { Posterior wall thickening (\%) }\end{array}$ & $\begin{array}{l}75(13) \\
72(15) \\
456(73) \\
28(6)\end{array}$ & $\begin{array}{l}74(14) \\
70(13) \\
473(51) \\
25(7)\end{array}$ & $\begin{array}{l}64(15) \\
64(15) \\
455(63) \\
31(8)\end{array}$ & $\begin{array}{l}67(13) \\
67(13) \\
473(61) \\
27(9)^{\star}\end{array}$ \\
\hline
\end{tabular}

Difference between pairs of values: ${ }^{\star} p<0.05,{ }^{\star \star} p<0.01,{ }^{\star \star \star} p<0.001$.

Table 4 Relation between electrocardiographic and echocardiographic results (adults)

\begin{tabular}{|c|c|c|c|c|c|}
\hline & Normal subjects & $\begin{array}{l}\text { LV outflow } \\
\text { obstruction }\end{array}$ & Hypertension & $\begin{array}{l}\text { Hypertrophic } \\
\text { cardiomyopathy }\end{array}$ & Athletes \\
\hline $\begin{array}{l}\text { No of subjects } \\
\mathrm{Q} \text { wave to minimum dimension (ms) } \\
\mathrm{Q} \text { wave to } \mathrm{A}_{2} \text { (ms) } \\
\text { Measured } \mathrm{QT} \text { to minimum dimension (ms) }\end{array}$ & $\begin{array}{r}14 \\
460(44) \\
435(43) \\
84(33)\end{array}$ & $\begin{array}{l}30 \\
450(64) \\
\mathrm{NC} \\
78(66)\end{array}$ & $\begin{array}{r}14 \\
435(79) \\
439(66) \\
39(99)\end{array}$ & $\begin{array}{l}20 \\
468(71) \\
482(63)^{\star} \\
62(72)\end{array}$ & $\begin{array}{l}14 \\
403(50)^{\star \star} \\
407(38) \\
22(63)^{\star \star}\end{array}$ \\
\hline
\end{tabular}

Difference from normal ${ }^{\star} \mathrm{p}<0.05 ;{ }^{\star}{ }^{\star} \mathrm{p}<0.01$

NC, not calculated; LV, left ventricular. 


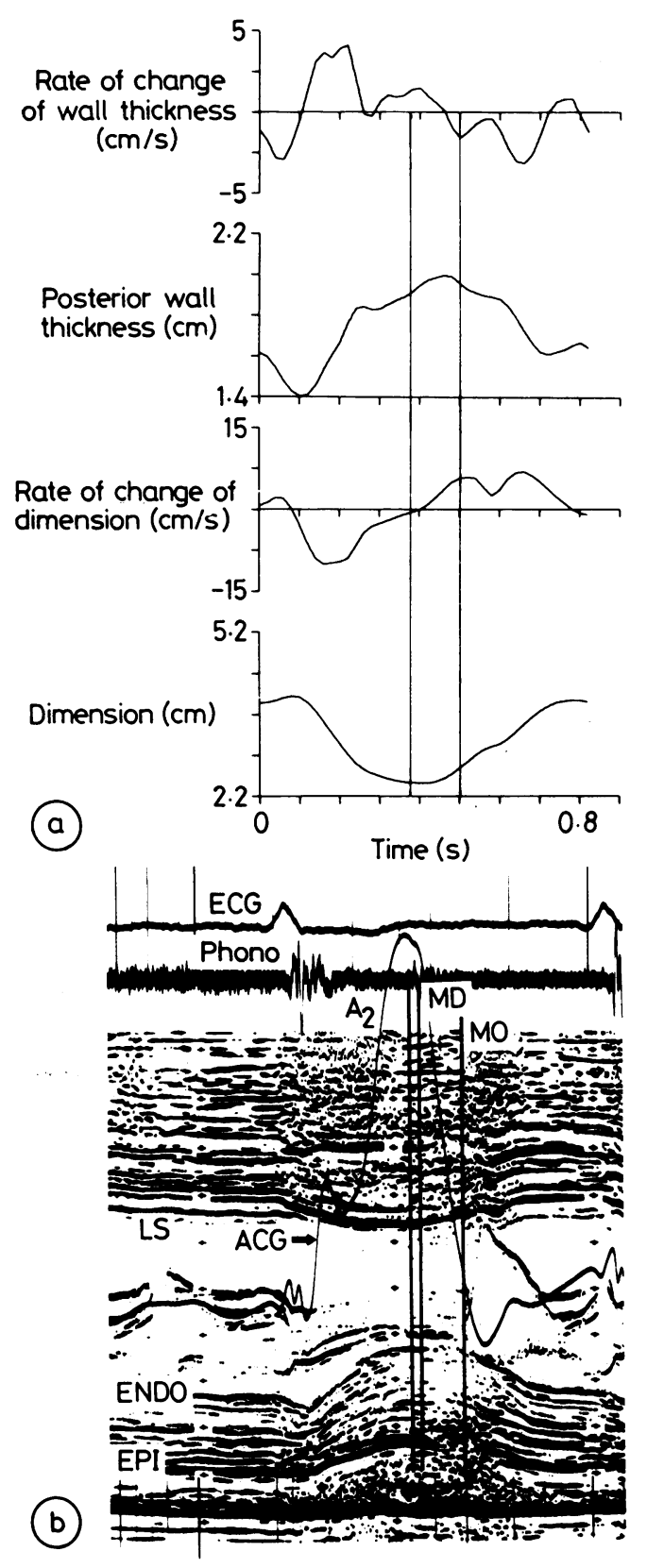

Fig. 2 (a) Set of computer plots from (b) digitised echocardiogram recorded simultaneously with an electrocardiogram (ECG), apexcardiogram (ACG), and phonocardiogram (Phono) in a 56 year old woman with hypertension and electrocardiographic strain. The two vertical lines on the plots correspond to aortic valve closure $\left(A_{2}\right)$ and mitral valve opening $(M O)$, the latter being determined from another complex. Note the delay in $M O$ in respect to $M D(100$ ms) and reduced rates of dimension increase and posterior wall thinning. Other abbreviations as in Fig. 1. associated with impaired systolic function, and previous authors have related this with $\mathrm{T}$ wave changes, particularly in patients with volume overload of the ventricle in whom cavity dilatation has occurred.$^{14}$ In general, systolic function was well preserved in our patients, although in the group with secondary left ventricular hypertrophy those with strain had rather lower values of peak velocity of circumferential fibre shortening and shortening fraction than those without. This finding was, however, confined to adults and was influenced by the lower values in the hypertensive group. In addition, all patients with secondary left ventricular hypertrophy had increased resistance to ejection which would have modified the measurements of systolic function had the extent of hypertrophy itself been less than compensatory. Finally, all the patients with hypertrophic cardiomyopathy had normal systolic function, and all but two had striking repolarisation abnormalities. We conclude that any relation between abnormalities of systolic function and the development of repolarisation abnormalities was weak and, moreover, not consistent even in patients with secondary left ventricular hypertrophy.

Diastolic abnormalities are common in left ventricular hypertrophy and indeed are the most characteristic disturbance of ventricular function in both the primary and secondary forms. ${ }^{15-17}$ These abnormalities include prolongation of isovolumic relaxation, delay in mitral valve opening with respect to minimum left ventricular dimension, and a reduction in peak rates of posterior wall thinning and dimension increase during filling. Unlike the systolic measurements considered above, those made during diastole were not directly modified by the haemodynamic disturbance underlying the development of left ventricular hypertrophy. This would not have been the case had patients with valvar regurgitation been studied. One or more diastolic abnormalities were present in all the patients with primary or secondary hypertrophy, although they were not seen in the athletes. Patients with repolarisation abnormalities had a significantly greater reduction in posterior wall thinning and rate of dimension increase and a significantly greater delay in mitral valve opening than those without. Unlike the other relations considered above, these associations held throughout the whole population studied-athletes and patients. We conclude, therefore, that, of the variables studied, diastolic abnormalities correlate most closely with the presence of ST-T wave changes on the electrocardiogram.

The association between repolarisation and diastolic abnormalities is a suggestive one. Disturbances of relaxation also occur, although on a regional basis, in patients with ischaemic heart disease, as do the $T$ wave changes, and the same applies in patients with the syndrome of chest pain and normal coronary 
arteriogram. ${ }^{18}$ The possibility arises, therefore, that the correlation seen in patients with left ventricular hypertrophy is merely a special case of a more general relation between electrical and mechanical events. This view is probably an oversimplification. Comparison of QT interval with the duration of mechanical systole, taken here as the time interval from $Q$ wave to minimum dimension, showed that repolarisation was complete before the onset of outward wall motion, showing that diastolic events could not directly influence $T$ wave changes. Conversely, it is difficult to see how abnormal repolarisation could directly affect wall motion during relaxation and filling. It seems more likely, therefore, that any relation between the two results from some common factor influencing both; one possibility is a structural disturbance. For reasons described above, we do not believe this factor to be the increase in ventricular mass or wall thickness. Pathological hypertrophy, however, is frequently associated with myocardial fibrosis and fibre disorganisation. The former may be shown to be associated with an increase in regional echo amplitude, 19 itself correlated with both repolarisation abnormalities and disturbances of diastolic function. A possible objection to this mechanism is that collagen deposition is usually held to be an irreversible process, so that the reversion of $T$ wave changes after successful surgery is difficult to explain. Recent studies on collagen metabolism have, however, shown that in experimental models it may have surprising metabolic activity, ${ }^{20}$ so that the question of its deposition being irreversible must be reconsidered. A second possible mechanism explaining the association of $T$ wave changes and diastolic events is that both reflect the presence of some additional physiological disturbance. Subendocardial ischaemia has frequently been invoked as a pathogenic mechanism in patients with left ventricular hypertrophy. ${ }^{21}$ In part this may represent the development of hypertrophy disproportionate to the blood supply. In patients with pressure overload, the requirement for increased tension development will itself increase myocardial oxygen requirements. Cavity dilatation, paticularly in association with an increased stroke volume, might be expected to be associated with an increase in diastolic wall stress ${ }^{22}$ thus interfering with subendocardial flow. Finally, coronary artery flow is mainly diastolic in timing, so that disturbances of myocardial relaxation might themselves cause ischaemia. Indirect evidence that this is the case comes from the association between angina as a symptom and slow filling, ${ }^{7}-$ or wall thinning ${ }^{23}$ in patients with hypertrophic cardiomyopathy-and an abnormal pattern of coronary artery blood flow velocity in patients with aortic stenosis. ${ }^{24}$ Myocardial ischaemia is potentially reversible if the cause of the hypertrophy is removed, although if it were the only cause of $T$ wave abnormalities, it would perhaps be expected that they would show considerably more lability and regress much more rapidly after operation than is actually the case.

Several conclusions may be drawn from our results. Abnormal electrical recovery is not the necessary consequence of an increase in left ventricular wall thickness or mass. Similarly, it is independent of cavity dimensions and probably systolic function. Repolarisation changes are, however, consistently associated with abnormal early diastolic function, although the underlying mechanism by which this is brought about is not clear. Normal timing between electrical and mechanical events was maintained despite abnormal repolarisation in patients with secondary left ventricular hypertrophy. The connection between mechanical and electrical events does not appear to be a direct one; almost certainly both anatomical and physiological factors are involved, probably to a varying extent in individual patients and at different times in the natural history of their disease. $T$ wave abnormalities are, however, so common in patients with heart disease and are so widely used as the basis for making clinical decisions in individual patients that further elucidation of their underlying mechanism is likely to be of considerable benefit both in understanding the pathogenic mechanisms and in improving management.

\section{References}

1 Einthoven W, Fahr G, deWaart A. Ueber die Richtung und die manifeste Grösse der Potential-schwankungen im menschlichen Herzen und über den Einfluss der Herzlage auf die Form des Elektrokardiogramms. Pflugers Archiv für die gesemte Physiologie des Menschen und der Tiere 1913; 150: 275-315.

2 Cassels DE. Aspects of the ECG in left ventricular hypertrophy. In: Cassels DE, Ziegler RF, eds. Electrocardiography in infants and children. London: William Heineman Medical Books, 1966: 216-44.

3 Selzer A, Naruse DY, York E, Kahn KA, Matthews HB. Electrocardiographic findings in concentric and eccentric left ventricular hypertrophy. Am Heart f 1962; 63: 320 8.

4 Burgess MJ, Green LS, Millar K, Wyatt R, Abildskov $N$ JA. The sequence of normal ventricular recovery. Am N Heart F 1972; 84: 660-9.

5 Van Dam RT, Durrer D. Experimental study on the intramural distribution of the excitability cycle and on the form of the epicardial $\mathrm{T}$ wave in the dog heart in situ. Am Heart f 1961; 61: 537-42.

6 Goodwin JF. The frontiers of cardiomyopathy. Br Heart? f 1982; 48: 1-18.

7 St John Sutton MG, Tajik AJ, Gibson DG, Brown DJ, Seward JB, Giuliani ER. Echocardiographic assessment of left ventricular filling and septal and posterior wall $\frac{D}{\mathbb{D}}$ 离

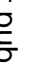


dynamics in idiopathic hypertrophic subaortic stenosis. Circulation 1980; 57: 512-20.

8 Shapiro LM. Physiological left ventricular hypertrophy. Br Heart f 1984; 52: 130-5.

9 Upton MT, Gibson DG. The study of left ventricular function from digitized echocardiograms. Prog Cardiovasc Dis 1978; 20: 359-84.

10 Boudoulas H, Geleris P, Lewis RP, Rittgers SE. Linear relationship between electrical systole, mechanical systole, and heart rate. Chest 1981; 80: 613-7.

11 Von Bibra H, Gibson DG, Nityanandan K. Effects of propanolol on left ventricular wall movement in patients with ischaemic heart disease. Br Heart $\mathcal{F} 1980$; 43: 293300.

12 Gould KL, Lipscomb K, Hamilton GW, Kennedy JW. Left ventricular hypertrophy in coronary artery disease. A cardiomyopathy syndrome following myocardial infarction. Am F Med 1973; 55: 595-601.

13 Dodge HT, Frimer M, Stewart DK. Functional evaluation of the hypertrophied heart in man. Circ Res 1974; 34 and 35 (suppl II): II-122-7.

14 Devereux RB, Reichek N. Repolarization abnormalities of left ventricular hypertrophy. Clinical, echocardiographic, and hemodynamic correlates. $f$ Electrocardiol 1982; 15: 47-53.

15 Gibson DG, Greenbaum R, Marier DL, Brown DJ. Clinical significance of early diastolic changes in left ventricular wall thickness. Eur Heart f 1980; 1 (suppl A): 157-63.

16 Gibson DG, Traill TA, Hall RJC, Brown DJ. Echocardiographic features of secondary left ventricular hypertrophy. Br Heart $\mathcal{F}$ 1979; 41: 54-9.
17 Chen W, Gibson D. Relation of isovblumic relaxation to left ventricular wall movement in man. Br Heart $\mathcal{F}$ 1979; 42: 51-6.

18 Gibson DG, Brown DJ. Abnormal left ventricular wall movement in patients with chest pain and normal coronary arteriograms. Relation to inferior $\mathrm{T}$ wave changes and mitral prolapse. Br Heart $\mathcal{F}$ 1979; 41: 385-91.

19 Shapiro LM, Moore RB, Logan-Sinclair RB, Gibson DG. Relation of regional echo amplitude to left ventricular function and the electrocardiogram in left ventricular hypertrophy. 1984; 52: 99-105.

20 Laurent GJ. Rates of collagen synthesis in lung, skin, and muscle obtained in vivo by a simplified method using [ $\left.{ }^{3} \mathrm{H}\right]$ proline. Biochem $\mathcal{F}$ 1982; 206: 535-44.

21 Hoffman JIE, Buckberg GD. Transmural variations in myocardial perfusion. In: Yu .PN, Goodwin JF, eds. Progress in cardiology, Philadelphia: Lea and Febiger, 1976: 37-89.

22 Grossman W, Jones D, McLaurin LP. Wall stress and patterns of hypertrophy in the human left ventricle. $\mathcal{F}$ Clin Invest 1975; 56: 56-64.

23 St John Sutton MG, Tajik AJ, Smith HC, Ritman EL. Angina in idiopathic hypertrophic subaortic stenosis. A clinical correlate of regional left ventricular dysfunction: a videometric and echocardiographic study. Circulation 1980; 61: 561-8.

24 Marcus ML, Doty DB, Hiratzka LF, Wright CB, Eastham CL. Decreased coronary reserve: a mechanism for angina pectoris in patients with aortic stenosis and normal coronary arteriograms. $N$ Engl f Med 1982; 307:1362-6. 